\title{
Diversity of Pathotypes and DNA Fingerprint Haplotypes in Populations of Magnaporthe grisea in Korea over Two Decades
}

\author{
Sook-Young Park, Michael G. Milgroom, Seong-Sook Han, Seogchan Kang, and Yong-Hwan Lee
}

First and fifth authors: School of Agricultural Biotechnology, Seoul National University, Suwon 441-744, Korea; second author: Department of Plant Pathology, Cornell University, Ithaca, NY 14853; third author: National Crop Experiment Station, Rural Development Administration, Suwon 441-100, Korea; and fourth author: Department of Plant Pathology, The Pennsylvania State University, University Park 16802.

Accepted for publication 30 May 2003.

\section{ABSTRACT}

Park, S.-Y., Milgroom, M. G., Han, S.-S., Kang, S., and Lee, Y.-H. 2003. Diversity of pathotypes and DNA fingerprint haplotypes in populations of Magnaporthe grisea in Korea over two decades. Phytopathology 93:1378-1385.

Using isolates collected over 2 decades, we determined the population structure and dynamics of the rice blast fungus, Magnaporthe grisea, in Korea at both the genotypic and phenotypic levels. Pathotype analysis on 6,315 isolates collected from 328 rice cultivars from 1981 to 2000 revealed the presence of a total of 91 pathotypes. Among these 91 pathotypes, nine dominated, comprising $76.5 \%$ of the isolates. The expected number of pathotypes (corrected for sample size) increased significantly during the course of this study. On average, six (ranging from 0 to 20) new commercial cultivars were introduced annually between 1981 and 1998. However, the overall cultivar diversity, estimated using the Shannon index, was low. Most of the new cultivars were not planted to a large area because the seven most common cultivars each year occupied over $70 \%$ of the rice-cultivated area. The frequencies of the nine dominant pathotypes from these seven cultivars were highly correlated with those from the entire set of cultivars. To understand genetic diversity within and between pathotypes, 176 isolates collected from 1984 to 1999 were randomly sampled and analyzed by DNA fingerprinting. High similarities were observed among isolates; overall similarities were greater than $63 \%$ in combined MGR586 and MAGGY DNA fingerprints. Unlike most other populations of $M$. grisea, DNA fingerprints showed no clear lineage structure. No groups were supported by bootstrap values greater than $10 \%$. Furthermore, there was no significant correlation between DNA fingerprint similarities and pathotypes. Genetic similarity was significantly greater $(P<0.001)$ within years than between years, although the difference was small. Our data suggest that $M$. grisea populations in Korea have been mostly dominated by a single clonal lineage. We cannot conclude from these data that selection by the host population has been a major force in the evolution of M. grisea in Korea.
Compatibility of plant-pathogen interactions is governed by the gene-for-gene model in many pathosystems (3). Because emergence of new pathotypes (or races) of a pathogen can often break down host resistance that is based on a single resistance $(R)$ gene, the mechanisms underpinning pathotype variation, especially the sources and dynamics of new pathotypes, have been extensively investigated in several pathosystems that follow the gene-for-gene model. Rice blast, caused by Magnaporthe grisea (Hebert) Barr, is one such system $(9,10,31,32,34)$.

Management of rice blast through breeding of blast-resistant cultivars has had only limited success due to frequent breakdown of resistance under field conditions $(2,6,18)$. The emergence of pathotype variation in $M$. grisea populations has been proposed as the principal mechanism involved in loss of resistance (26). Although it is generally accepted that pathotype frequencies in $M$. grisea change in nature (18), the degree of its variability has been a controversial subject $(20,26)$. It is generally agreed that blast fungus populations change in response to cultivation of resistant cultivars. Recent studies combining DNA fingerprinting and pathotype analysis have shown that some $M$. grisea populations are composed of discrete clonal lineages, and that individual lineages consist of a limited set of pathotypes $(21,22,29,36,37)$.

Corresponding author: Y.-H. Lee; E-mail address: yonglee@snu.ac.kr

Publication no. P-2003-0911-01R

(C) 2003 The American Phytopathological Society
The degree of correlation between lineages and pathotypes varies among populations from strong in the United States, Colombia, and Europe, to moderate in the Philippines and Vietnam $(5,7$, $8,21,22,36)$. In Japan, however, no clear correlation was observed between lineages and pathotypes (7). Current populations in Japan appear to comprise only two lineages based on DNA fingerprints with MGR586 (7). However, archival isolates from the 1970s appear to be associated with different lineages from the two contemporary ones, suggesting that lineage composition in Japan has changed markedly over time. Although the causes of this shift are not known, one hypothesis is that the lineages that existed during the 1970s disappeared entirely because of the introduction of resistant cultivars with which all members of a lineage were incompatible.

The population of $M$. grisea in Korea has been monitored for pathotypes defined using eight Korean differential cultivars over the last 20 years by the Rural Development Administration (RDA; Suwon, Korea). Han et al. (15) reported that the distribution of pathotypes changed over time; new pathotypes appeared and existing pathotypes disappeared. They suggested that changes in $M$. grisea pathotypes in Korea might be associated with changes in host plant populations. Major changes have occurred in cultivar composition since the 1970s. In particular, a japonica $\times$ indica hybrid cultivar, named Tongil, and related hybrid cultivars were developed and released in the early 1970s. The area planted with Tongil-type cultivars rapidly increased until 1977 (Fig. 1). During this period, there had been no severe blast epidemics. However, the cultivated acreage for these cultivars dramatically decreased 
after 1978 when severe blast epidemics swept through rice fields. By 1993, Tongil-type cultivars had almost completely disappeared in Korea and had been replaced by new japonica cultivars. In a preliminary study of $M$. grisea populations in Korea, Han (14) analyzed a small number of isolates using DNA fingerprints with MGR586, and no clear lineage structure was observed. Han (14) reported a high degree of fingerprint similarities among isolates and only a weak correlation between DNA fingerprint similarity and pathotypes. Although changes in the host population have been clearly documented during the last 20 years, a parallel analysis of the structure and dynamics of $M$. grisea populations during the same period has not been done.

The objectives of this study were (i) to determine if changes in pathotype diversity and composition could be observed over time and, if so, whether these changes correlated with host plant diversity, (ii) to determine the genetic structure of $M$. grisea populations in Korea over the last 20 years based on DNA fingerprinting, and (iii) to determine the correlation between pathotypes and DNA fingerprint similarity over time. The large set of isolates collected over 20 years in Korea provided a unique opportunity to investigate whether host selection pressure has influenced the structure and dynamics of $M$. grisea populations at both the pathotype and genotype levels.

\section{MATERIALS AND METHODS}

Rice cultivar and M. grisea pathotype surveys. Information on rice cultivars and estimates of cultivated area of each cultivar during 1965 to 2000 were obtained from the statistical database of the Ministry of Agriculture and Forest (MAF) of Korea. The cultivated area includes both paddy and upland fields. Cultivar diversity was estimated using the Shannon diversity index (16), $H=-\Sigma p_{i} \ln p_{i}$, where $p_{i}$ is the proportion of cultivated area planted to the $i$ th cultivar.

Pathotype data for $M$. grisea was obtained from RDA. Pathotypes of $M$. grisea isolates have been monitored in farmers' fields and blast nurseries by RDA since 1978 when Korea experienced severe epidemics of rice blast (15). The number of isolates sampled differed annually, because it was based on disease incidence at each location. Isolates of $M$. grisea collected in these surveys were tested for virulence on a set of eight Korean differential cultivars to determine their pathotypes $(1,14)$. Korean differentials consist of one indica (cv. Tetep), four japonica (cvs. Kanto51, Nongbaeg, Jinheung, and Nakdong), and three Tongiltype cultivars (cvs. Taebaeg, Tongil, and Yushin). Disease reaction of each differential cultivar was recorded 5 to 7 days after inoculation by the standard index $(1,14)$. For most of 6,315 isolates sampled from 1981 to 2000 , data are available for pathotype, cultivar of origin, and geographic origin. For 1986, 1989, and 2000 , information on the cultivar of origin is not available for many of the isolates.

Analysis of pathotype diversity. We encountered a number of challenges in analyzing pathotype diversity. First, because these isolates were collected from a large number of cultivars each year and the composition of cultivars shifted during the sampling period, only a small set of the same cultivars (described below) has been sampled for an extended period of time. Second, the number of isolates from individual cultivars is not necessarily proportional to the cultivated area for each cultivar. Instead, overall, it is roughly proportional to disease incidence on individual cultivars. Therefore, the RDA collection is appropriate for estimating the richness component of pathotype diversity (the number of pathotypes) but not the evenness component, which ideally would be based on estimates of pathotype frequencies from a random sample of the entire $M$. grisea population (12). The third problem is that sample sizes varied considerably over years, ranging from $N=69$ in 1991 to $N=650$ in 1983 (Table 1). Therefore, to compare pathotype richness between years, a rarefaction analysis was conducted to standardize the richness expected in each sample based on the smallest sample size. Rarefaction analysis has previously been used for comparing diversity in populations of Phytophthora infestans in Mexico (12) and $M$. grisea in the Indian Himalayas (19). Rarefaction analysis of pathotype richness in Korea was done using the program Rarefac.c (12).

DNA extraction and Southern blot hybridization. A total of 176 isolates of M. grisea collected from 1984 to 1999 were randomly sampled from the larger collection and subjected to DNA fingerprinting analysis to determine their genetic relatedness. This included all isolates available from the RDA for the period between 1984 and $1987(N=22)$ and a random sample of isolates from the following years: 1988, 1991, 1993, 1996, 1998, and 1999. Fungal isolates were grown in $50 \mathrm{ml}$ of complete medium broth (6 $\mathrm{g}$ of yeast extract, $6 \mathrm{~g}$ of casamino acids, and $10 \mathrm{~g}$ of sucrose per liter) at $25^{\circ} \mathrm{C}$ for 5 days. Genomic DNA was isolated as described previously (27). DNA concentration was estimated with a TKO 100 minifluorometer (Hoefer, San Francisco, CA) with the DNA-specific fluorescent dye Hoechst 33258. One microgram of DNA from each isolate was digested with EcoRI and fractionated in $0.7 \%$ agarose gels at $20 \mathrm{~V}$ for $36 \mathrm{~h}$ in $0.5 \%$ Tris-borate-EDTA buffer. Fractionated DNAs were transferred to Hybond N+ membrane (Amersham International, Little Chalfont, England) using $5 \times \mathrm{SSC}(1 \times \mathrm{SSC}$ is $0.15 \mathrm{M} \mathrm{NaCl}$ plus $0.015 \mathrm{M}$ sodium citrate).

DNA fingerprinting was conducted using two different repetitive DNAs (transposable elements), MGR586 (13) and MAGGY

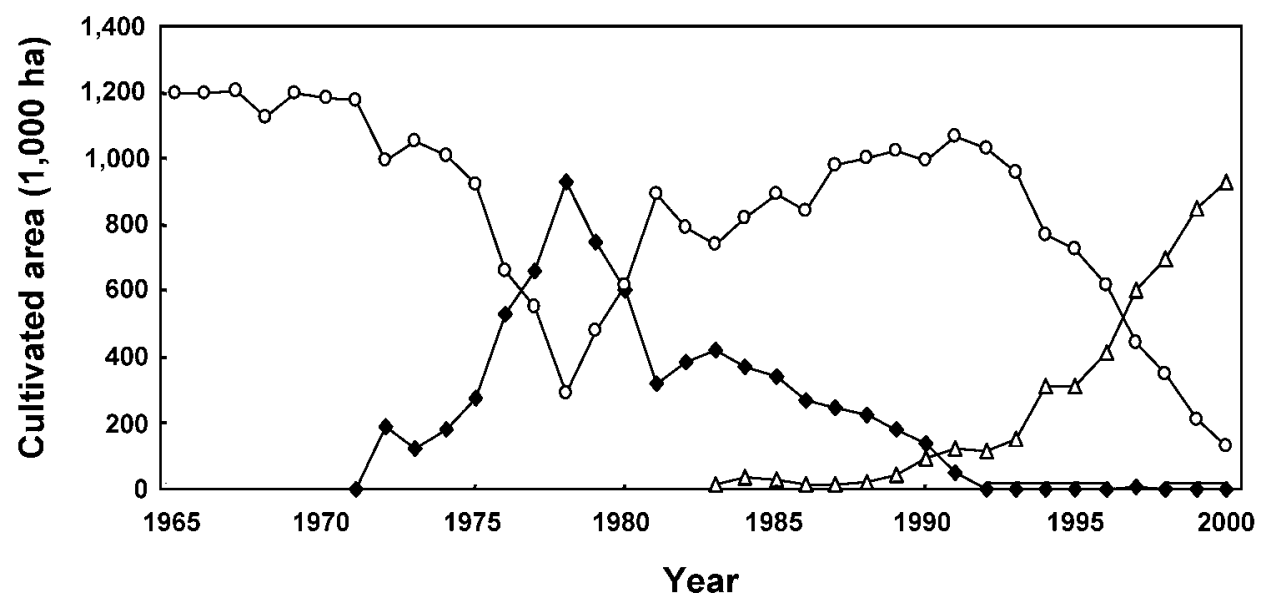

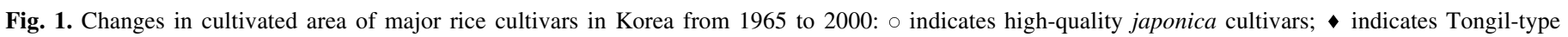
cultivars; and $\Delta$ indicates high-quality and high-yielding japonica cultivars. 
(11), as probes. MGR586 probe was prepared by isolating the 1.4-kb SalI-BamHI restriction fragment from plasmid pCB586 (provided by B. Valent, Du Pont Co., Wilmington, DE); MAGGY (11) probe was prepared by isolating the $0.56-\mathrm{kb}$ SalI-BamHI fragment from plasmid pMGY23 (provided by M. Farman, University of Kentucky, Lexington). Probes were individually labeled with ${ }^{32} \mathrm{P}$-dCTP by random priming. Genomic DNA blots were hybridized with each probe at $65^{\circ} \mathrm{C}$ overnight in $6 \times \mathrm{SSPE}(1 \times \mathrm{SSPE}=$ $0.18 \mathrm{M} \mathrm{NaCl}, 1 \mathrm{mM}$ EDTA, and $10 \mathrm{mM}$ sodium phosphate $[\mathrm{pH}$ 7.4]) containing $1 \%$ sodium dodecyl sulfate (SDS) and $100 \mu \mathrm{g}$ of denatured salmon sperm DNA per ml. After hybridization, blots were washed twice in $2 \times \mathrm{SSPE}, 0.1 \% \mathrm{SDS}$ for $5 \mathrm{~min}$ at $65^{\circ} \mathrm{C}$ followed by two washes in $0.1 \times$ SSPE containing $0.1 \%$ SDS for $30 \mathrm{~min}$ at $65^{\circ} \mathrm{C}$. Signals were detected by autoradiography using $\mathrm{X}$-ray film.

DNA fingerprinting analysis. DNA fingerprints were visually scored from autoradiograms using a binary system (1 for presence and 0 for absence at each band position). Distinct DNA fingerprints among isolates were considered haplotypes. Similarities between DNA fingerprints among all pairs of isolates were calculated using Nei and Li's index (25) (also known as the Dice

TABLE 1. Summary of pathotype survey of Magnaporthe grisea isolates collected from rice in Korea during 1981 to 2000

\begin{tabular}{ccccc}
\hline Year & $\begin{array}{c}\text { No. of } \\
\text { isolates }\end{array}$ & $\begin{array}{c}\text { No. of cultivars } \\
\text { sampled }\end{array}$ & $\begin{array}{c}\text { No. of observed } \\
\text { pathotypes }^{\mathrm{a}}\end{array}$ & $\begin{array}{c}\text { No. of expected } \\
\text { pathotypes }\end{array}$ \\
\hline 1981 & 358 & 51 & 8 & 3.81 \\
1982 & 600 & 61 & 17 & 8.45 \\
1983 & 650 & 62 & 16 & 8.80 \\
1984 & 510 & 79 & 16 & 8.01 \\
1985 & 334 & 49 & 22 & 12.50 \\
1986 & 296 & $-\mathrm{b}$ & 21 & 11.39 \\
1987 & 123 & 40 & 17 & 12.31 \\
1988 & 129 & 45 & 11 & 7.91 \\
1989 & 10 & - & 6 & n.d. \\
1990 & 77 & 25 & 10 & 7.77 \\
1991 & 69 & 42 & 12 & 9.95 \\
1992 & 237 & 77 & 22 & 11.30 \\
1993 & 455 & 76 & 28 & 16.09 \\
1994 & 458 & 114 & 24 & 14.45 \\
1995 & 377 & 91 & 22 & 13.98 \\
1996 & 353 & 23 & 50 & 24.71 \\
1997 & 139 & 19 & 30 & 20.34 \\
1998 & 147 & 29 & 24 & 15.71 \\
1999 & 567 & 134 & 31 & 14.36 \\
2000 & 426 & $>79$ & 27 & \\
\hline
\end{tabular}

a Expected number of pathotypes was estimated after correcting for sample sizes by rarefaction analysis.

${ }^{\mathrm{b}}$ Data not available.

${ }^{\mathrm{c}}$ This sample was not included in rarefaction analysis due to small size $(N=$ $10)$.

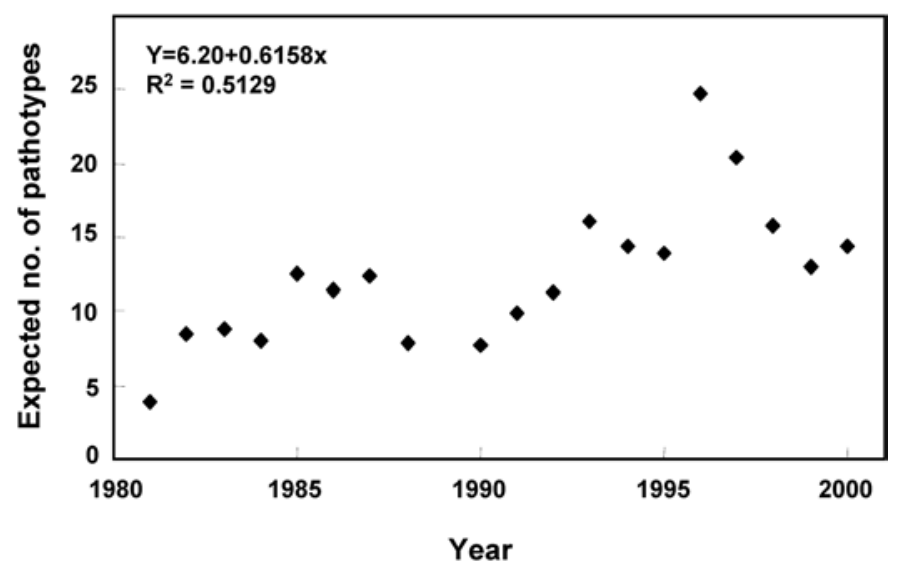

Fig. 2. Expected number of pathotypes (richness) from 1981 to 1999 corrected for the smallest sample size by rarefaction analysis (12). coefficient): $S_{x y}=2 N_{x y} /\left(N_{x}+N_{y}\right)$, where $N_{x}$ and $N_{y}$ are the number of fragments in isolates $X$ and $Y$, respectively, and $N_{x y}$ is the number fragments shared by $X$ and $Y$. A phenogram was constructed from the similarity matrix based on MGR586, MAGGY, and the combined data set using the unweighted pair group method using arithmetic means (UPGMA) in the computer program NTSYS (28; Exeter Software, Setauket, NY). The robustness of clusters in the UPGMA-based phenograms was determined by bootstrapping using 1,000 replications in the program WINBOOT (35).

Correlation analysis between pathotypes and DNA fingerprints. To determine the correlation between pathotypes and DNA fingerprint similarity among isolates, a matrix comparison technique was used (24). We tested the null hypothesis that DNA fingerprint similarity was not greater among isolates with the same pathotypes than when pathotypes were assigned at random to isolates. For this analysis, the combined set of MGR586 and MAGGY data were used. Significance tests were done by 1,000 randomizations as described by Liu et al. (23).

\section{RESULTS}

Pathotype diversity during 1981 to 2000. Pathotypes were determined for 6,315 M. grisea isolates collected from 328 rice cultivars from 1981 to 2000 (Table 1). In total, 91 pathotypes were found in this sample. With only a few exceptions, more than 10 pathotypes were detected in each year. In 1996, 50 pathotypes were detected among 353 isolates. Because the number of isolates sampled each year varied markedly, estimates of richness were corrected for sample size by rarefaction analysis. In general, the expected number of pathotypes (corrected for the smallest sample size) increased significantly during the course of this study $(P<$ 0.001) (Fig. 2). Among the 91 pathotypes, nine dominated the Korean M. grisea population, constituting $76.5 \%$ of all isolates during the entire collection period (Table 2; Fig. 3). Pathotype KJ301 was the most prevalent and alone constituted $23.1 \%$ of the total population. The other eight common pathotypes were sampled at frequencies from 1.5 to $13.3 \%$ (Table 2). The rest of the 82 pathotypes each occurred at a frequency of less than $1 \%$, but together constituted $23.5 \%$ of the population (Table 2). The nine dominant pathotypes were sampled frequently during the collection period, while 30 of the minor pathotypes appeared

TABLE 2. Frequencies of the nine most common pathotypes of Magnaporthe grisea from all cultivars and those sampled from the seven most common cultivars during 1981 to 1999

\begin{tabular}{|c|c|c|c|c|c|}
\hline \multirow[b]{2}{*}{ Pathotype $^{a}$} & \multicolumn{2}{|c|}{ All cultivars } & \multicolumn{3}{|c|}{ Most common cultivars ${ }^{b}$} \\
\hline & $\begin{array}{l}\text { No. of } \\
\text { isolates }\end{array}$ & $\%$ & $\begin{array}{l}\text { No. of } \\
\text { isolates }\end{array}$ & $\%$ & $\begin{array}{c}\text { No. } \\
\text { compatible }^{c}\end{array}$ \\
\hline KJ-301 & 1,288 & 23.1 & 360 & 29.1 & 7 \\
\hline $\mathrm{KJ}-401$ & 745 & 13.3 & 296 & 23.9 & 6 \\
\hline KJ-105 & 725 & 13.0 & 199 & 16.1 & 7 \\
\hline $\mathrm{KJ}-201$ & 549 & 9.8 & 98 & 8.0 & 7 \\
\hline KJ-101 & 317 & 5.7 & 49 & 4.0 & 6 \\
\hline KJ-409 & 288 & 5.2 & 24 & 1.9 & 5 \\
\hline KI-1117 & 171 & 3.1 & 19 & 1.5 & 6 \\
\hline KI-413 & 101 & 1.8 & 19 & 1.5 & 4 \\
\hline KJ-107 & 85 & 1.5 & 25 & 2.0 & 7 \\
\hline Others $^{\mathrm{d}}$ & 1,314 & 23.5 & 148 & 12.0 & - \\
\hline Total & $5,583^{\mathrm{e}}$ & 100.0 & 1,237 & 100.0 & - \\
\hline
\end{tabular}

a Designation of pathotypes by Korean differential system (15).

b The seven most common cultivars accounted for a major proportion of the area planted to rice in Korea over a 20 -year period (Fig. 4B).

c The number of common cultivars (out of seven) from which each pathotype was isolated.

d This category comprises 82 other pathotypes, each at a frequency of less than $1 \%$.

e Isolates collected in 1986, 1989, and 2000 were not included in this analysis because information on cultivar of origin is not available for many of them. 
in just 1 year each from 1981 to 2000 . When the nine major pathotypes were analyzed with respect to the cultivars from which they were isolated, the seven most common cultivars were the major sources. The frequencies of these nine pathotypes in the total population were highly correlated with those from the seven common cultivars $(r=0.95 ; P<0.001)$ (Table 2; Fig. 3).

Rice cultivar diversity. To test for an association between pathogen diversity and rice cultivar diversity, we utilized archived data on the composition and planted acreage of rice cultivars for 1965 to 2000. Changes in the major groups of cultivars from 1965 to 2000 are shown in Figure 1. Before the introduction of Tongil and Tongil-type cultivars in 1971, all cultivars planted in Korea were high-yielding japonica rice. By 1978 , over $70 \%$ of total cultivated rice consisted of Tongil-type cultivars. However, since the blast epidemic in 1978, the area planted with Tongil-like cultivars has significantly declined and high-quality japonica cultivars have replaced them.

On average, six (range 0 to 20) new commercial cultivars were introduced annually between 1981 and 1998 (Fig. 4A). Most of the newly introduced cultivars however were not planted to a large area. The seven most common cultivars over the period of 1981 to 1998 accounted for more than one-third of the rice grown in Korea (Fig. 4B). In 1981, these seven cultivars accounted for $47 \%$ of the total rice fields, and the proportion further increased to over $70 \%$ in 1992. Since 1992, their cultivation has decreased, as the planting areas for some newer cultivars gradually increased (Fig. 4B). For instance, in 1998, only $34 \%$ of the rice fields were planted with these seven cultivars.

The diversity of cultivars each year was estimated using the Shannon index (Fig. 4C). During 1991 to 1993, when the seven most common cultivars occupied over $60 \%$ of the area, the overall cultivar diversity was low. However, cultivar diversity gradually increased after 1994 (Fig. 4C). When cultivar diversity was compared with pathotype diversity during the entire period, no correlation was observed between them $(r=0.35 ; P=0.173)$.

DNA fingerprint variation. We randomly sampled 176 isolates of M. grisea collected from 1984 to 1999 and analyzed their DNA fingerprints. We considered this sample as representative of the total population because the frequencies of the nine dominant pathotypes in the 176 isolates fingerprinted are highly correlated with those of the total population over 16 years $(r=0.89 ; P=$ $0.004)$. High similarity was observed among all isolates in their DNA fingerprints with both MGR586 and MAGGY. Representative autoradiograms of MGR586 and MAGGY are shown in Fig-

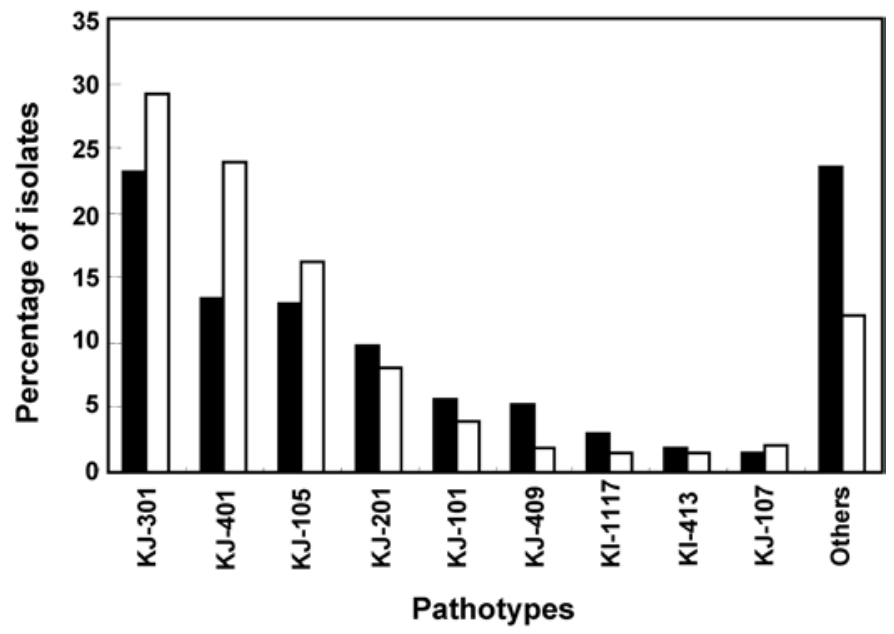

Fig. 3. Frequency of the nine most common pathotypes from all cultivars and those sampled from the seven most common cultivars during 1981 to 1999: black bars indicate total collection; and white bars indicate seven common cultivars. ure 5. More than 65 and $75 \%$ similarities were observed by DNA fingerprinting analyses with MGR586 and MAGGY, respectively. Neither analysis showed clear lineage structure among the isolates tested (data not shown). Because of the lack of clear structure for either probe alone, we combined data for both to analyze the overall genetic similarities. With data from MGR586 and MAGGY DNA fingerprints combined, all pairwise similarities were greater than $63 \%$. As with data from individual probes, cluster analyses of the combined DNA fingerprints showed no clear lineage structure (Fig. 6). Nonetheless, 13 subgroups were arbitrarily defined as those with fingerprint similarities of more than 70 to $85 \%$ because they tend to correlate with the years in which isolates were collected (Fig. 6). However, none of these groups are supported by bootstrapping $(<10 \%$ support). Isolates in each year were found in only one to four fingerprint subgroups (Table 3). For example, all 22 isolates sampled in 1993, with 10 different pathotypes, were found in a single subgroup (subgroup 2). Similarly, only two subgroups were present in 1998 and three subgroups in 1999. Matrix comparison tests showed that DNA fingerprint similarities were significantly greater within years than between years. Because of the small sample sizes available in 1984 to $1987(N=22$ in total), the 1984 to 1987 samples were pooled for this analysis. The aver-

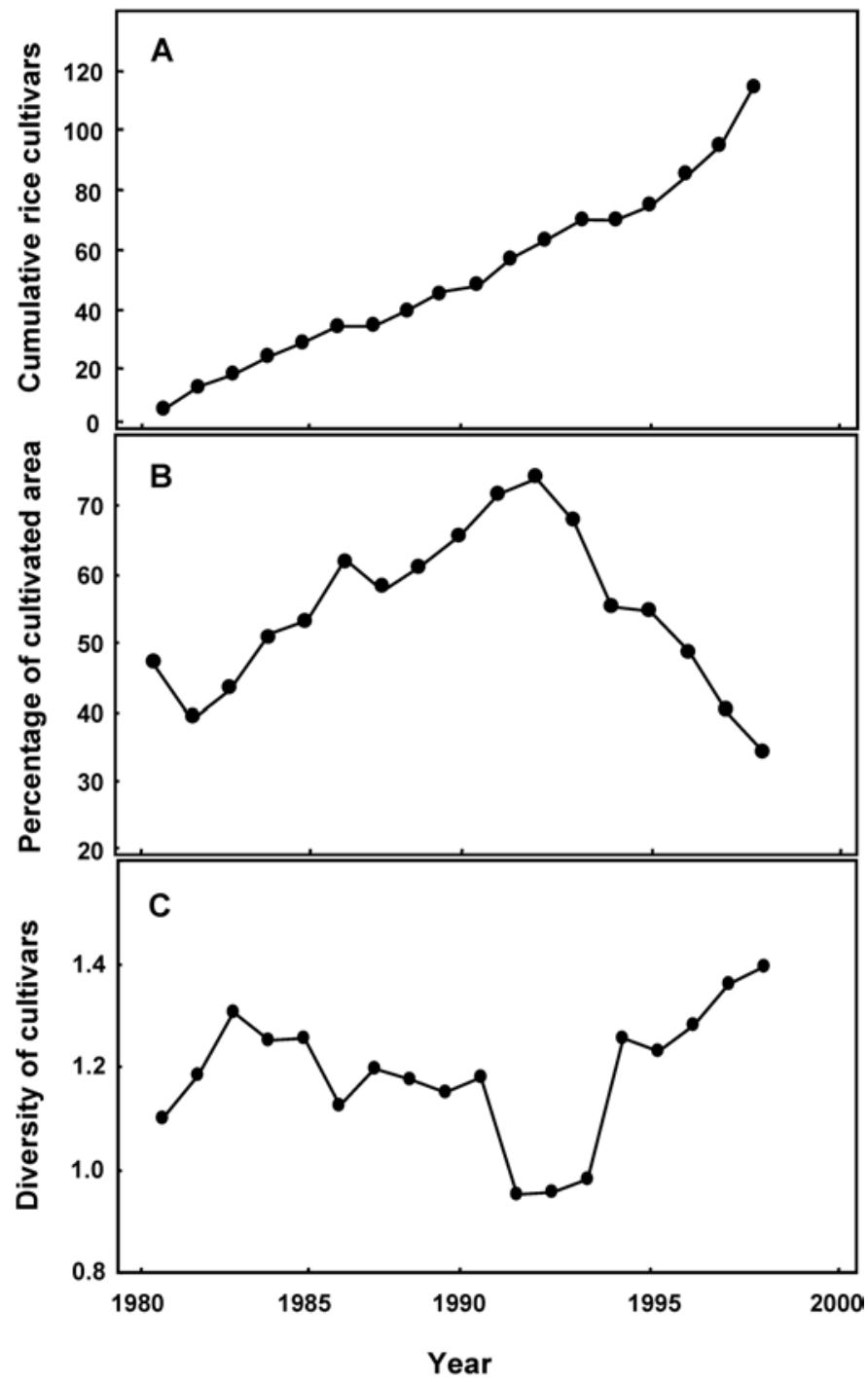

Fig. 4. Number, area, and diversity of rice cultivars in Korea during 1981 to 1998. A, The cumulative number of rice cultivars introduced in the field over time. B, Percentage of cultivated area planted to the seven most common cultivars. C, The diversity of all rice cultivars estimated by the Shannon index. 
age fingerprint similarity within years was $76 \%$, whereas the expected similarity with fingerprints under the null hypothesis, with isolates randomly assigned to years, was only $74 \%$. Although this difference in similarity within and between years is not large, it is statistically significant $(P<0.001)$, indicating an association between fingerprint similarity and year. In contrast to a previous study on the $M$. grisea population in Korea (15) showing a correlation between pathotypes and DNA fingerprint lineages, we found no significant correlation between pathotypes and DNA fingerprint similarity. The average DNA fingerprint similarity within pathotypes was $73 \%$, whereas the expected similarity with fingerprints under the null hypothesis, with isolates randomly assigned to pathotypes, was 74\% $(P=$ 0.583).

\section{DISCUSSION}

We studied the composition and dynamics of pathotypes in $M$. grisea collected from rice in Korea for over two decades. We also investigated how the diversity of rice cultivars planted in Korea since 1981 is correlated to the diversity of pathotypes. Unlike other studies, we found no evidence for the host population selecting for specific sets of pathotypes, nor did we find a clear clonal lineage structure in this population.

Although we found a total of 91 pathotypes among 6,315 isolates over 20 years, nine pathotypes constituted more than three- fourths $(77 \%)$ of the total population. These nine pathotypes were consistently detected over 2 decades, with other pathotypes being found much less frequently. The expected number of pathotypes was adjusted to the smallest sample size in each year by rarefaction analysis, and pathotype diversity increased consistently over this time period. Our initial hypothesis was that cultivar diversity might be responsible for the increase in pathotype diversity and that we would observe a correlation between cultivar and pathotype diversities. However, our results do not support this hypothesis. There could be several causes for the lack of such correlation. First, because related cultivars may share the same $R$ genes, the number and diversity of different cultivars planted each year may not properly reflect the degree of $R$ gene diversity. Thus, higher cultivar diversity per se may not be an appropriate indicator for the degree of selection imposed on the pathogen population for greater pathotype diversity. In addition, if the most common pathotypes are compatible with a large number of cultivars planted during this period, the selection pressure from increased cultivar diversity (as well as $R$ gene diversity) may be minimal. Another possible explanation is that the set of Korean differential cultivars used for defining pathotypes in this study (15) may not reveal pathotype variation adequately. Korean differentials consist of one indica, four japonica, and three Tongiltype cultivars. Because Tongil-type cultivars have not been planted in large areas since the mid-1980s and indica cultivars are rarely ever planted, the latter four cultivars may not be appro-

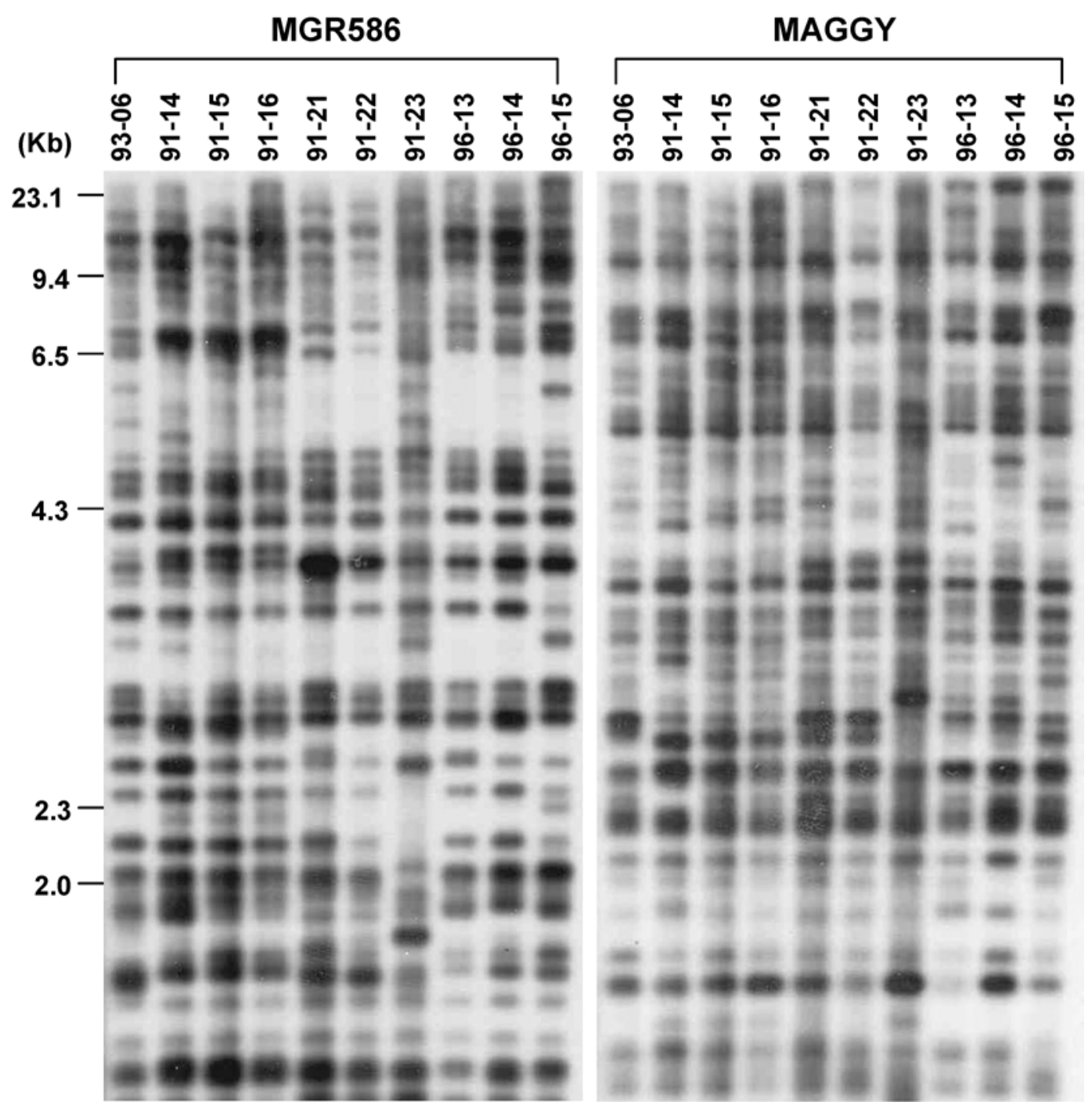

Fig. 5. DNA fingerprinting of 10 representative isolates of Magnaporthe grisea using MGR586 and MAGGY as probes. The first two digits of isolate names indicate the year when the isolates were collected. 
priate for differentiating current pathotypes that are relevant with respect to the current cultivars being planted. When we analyzed the pathotypes without using the Tongil-type and indica differentials, we found all 16 possible pathotypes defined by four differentials in most of the years, suggesting that these differentials may not provide adequate information about the pathotype diversity and that additional differentials similar to contemporary rice cultivars may be needed. Because Korean differentials have not been analyzed genetically for their $R$ gene compositions, we do not know how many distinct $R$ genes are present in them.

DNA fingerprinting analysis with MGR586 and MAGGY of 176 M. grisea isolates collected over 16 years did not show any clear lineage structure in Korea. The lack of a clear lineage structure, similar to what has been observed in Japan (7), may be due to a number of factors. First, selection by the host population may have resulted in an extreme genetic bottleneck in the pathogen population such that the Korean population of M. grisea may have been derived from a single genotype. The almost complete change of cultivars from japonica to Tongil-type and back to japonica may have imposed intense selection and a series of bottlenecks,

\section{Similarity index}

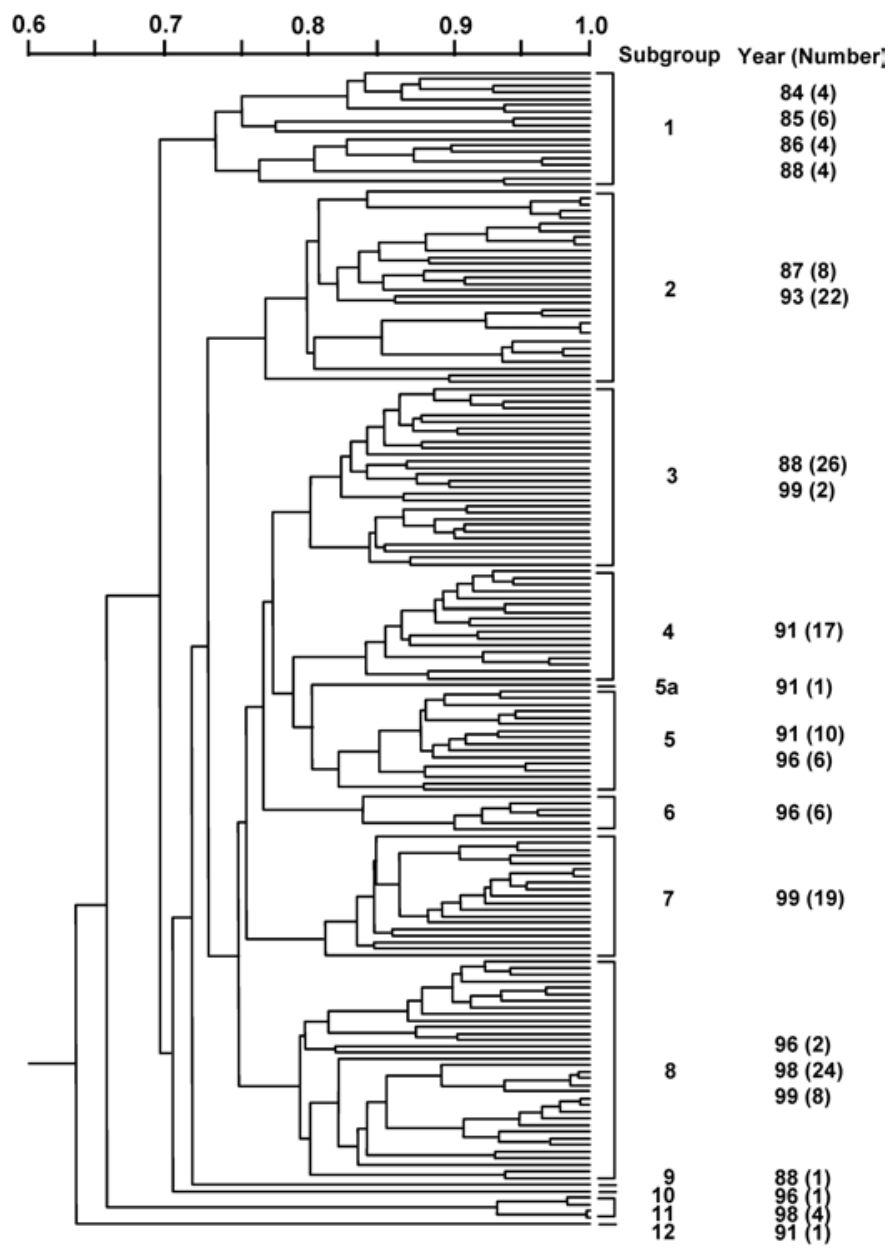

Fig. 6. Phenogram of the combined MGR586 and MAGGY fingerprint similarity of Magnaporthe grisea isolates collected in Korea from 1984 to 1999. This tree was constructed by unweighted pair-group method with arithmetic average (27). Numbers at the right indicate the years that isolates were collected; and numbers in parentheses indicate the number of isolates per year. Brackets at right indicate subgroups with similarities greater than 70 to $85 \%$, which were arbitrarily defined to illustrate the relationship between fingerprint similarity and year. None of the branches was supported by bootstrap values greater than $10 \%$. such that only a single lineage persisted in the population in Korea (since 1984). However, we cannot test this hypothesis because isolates collected prior to 1981 are not available. Furthermore, isolates used in DNA fingerprint analyses in this study were collected after Tongil-type cultivars were mostly replaced by japonica-type cultivars. Clear lineage structures of $M$. grisea populations have been identified in the United States, Colombia, the Philippines, and in Europe, although the number of lineages varied considerably in different areas $(7,8,29,30)$. However, in Japan, only two lineages were identified in a sample of isolates from 1993 to 1997 , whereas different lineages were detected there in the 1970s (7), suggesting that the 1970s lineages disappeared, presumably due to the introduction of resistant cultivars to which all members of the lineage were incompatible. This hypothesis also remains to be tested.

A corollary hypothesis to explain the lack of distinct lineages in Korea is that a single lineage was the most successful on the post-Tongil japonica cultivars and has out-competed less fit lineages, resulting in one lineage dominating the population. In this case, although the population may contain more lineages, they may not have been sampled during our fingerprinting analysis because of their low frequencies. The relatively rare haplotypes that are least similar to the rest of the population (subgroups 9, 10, 11, and 12; Fig. 4) may represent members of the rare lineages, although the bootstrap value is not strong enough to support them as distinct lineages. Variation within the dominant lineage may accumulate after reaching large populations sizes. This type of population structure is similar to the epidemic population structure proposed by Smith et al. (33) for pathogenic microorganisms.

A lineage structure also may be absent in Korea because of recombination. A clear lineage structure is expected only in strictly asexual populations, and therefore, we had to consider if $M$. grisea reproduces sexually in Korea. However, all 176 isolates are in the same mating type, MATI-1 (S. Y. Park and Y. H. Lee, unpublished data), strongly arguing against the possibility of sexual recombination. M. grisea appears to be asexual everywhere, except in a few special populations, including those in Indian Himalayas (19), Thailand, and southern China (17). The lack of clear lineage structure also could be explained by high mutation rates or reversals and convergence of MGR586 and MAGGY transpositions such that restriction fragments of the same size may not be homologous or identical by descent. This type of homoplasy has been documented for fingerprint genotypes of Sclerotinia sclerotiorum determined using a transposable element as a probe (4). The mutation rates of MGR586 and MAGGY used for fingerprinting in $M$. grisea have not been carefully studied. Also, loss of a transposon copy or convergent gain of a transposon to the same restriction fragment (or same size

TABLE 3. Summary of subgroup structure and DNA fingerprint haplotypes with MGR586 and MAGGY of Magnaporthe grisea isolates collected from rice in Korea during 1984 to 1999

\begin{tabular}{lccccc}
\hline \multirow{2}{*}{$\begin{array}{l}\text { Year } \\
\text { sampled }\end{array}$} & \multicolumn{5}{c}{ No. of } \\
\cline { 2 - 6 } & Isolates $^{\text {Haplotypes }}{ }^{\mathrm{a}}$ & Pathotypes & Cultivars $^{\mathrm{b}}$ & Subgroup $^{\mathrm{c}}$ \\
\hline $1984-1987$ & 22 & 22 & 16 & 17 & 1,2 \\
1988 & 31 & 31 & 8 & 18 & 3,9 \\
1991 & 29 & 29 & 10 & 24 & $4,5,5 \mathrm{a}, 12$ \\
1993 & 22 & 22 & 10 & 17 & 2 \\
1996 & 15 & 15 & 11 & 12 & $5,6,8,10$ \\
1998 & 28 & 28 & 12 & 6 & 8,11 \\
1999 & 29 & 29 & 12 & 20 & 8,7 \\
\hline
\end{tabular}

a Distinct DNA fingerprint patterns with MGR586 and MAGGY data combined.

b Number of cultivars from which the subsample of isolates was obtained.

c Subgroups of isolates with $\geq 70$ to $85 \%$ of DNA fingerprint similarity with MGR586 and MAGGY (Fig. 6). 
fragment) can give the appearance of recombination and distort the pattern expected for an asexual lineage. Because there is no clear fingerprint lineage structure in the Korean $M$. grisea population, it is not possible to see a correlation between pathotypes and fingerprint lineages. In other words, if there is only a single lineage, then pathotypes may be randomly associated with haplotypes in the lineage. High correlations between DNA fingerprints and pathotypes were observed in the populations of the United States and Colombia, but a low correlation was observed in the populations of the Philippines $(21,22,36)$. In Japan, however, no correlation was observed because the current population has only two lineages in which many pathotypes exist (7). Interestingly, there is a significant correlation between DNA fingerprint similarity and year of sampling in Korea. Because we analyzed DNA fingerprints from isolates obtained from different years in the same gel, we have ruled out the possibility of systematically misscoring DNA fingerprints. One possible explanation for this correlation would be for $M$. grisea to go through bottlenecks each year such that only a small sample of haplotypes survives to the next cropping season. In such a case, we might see a correlation within years because of founder effects each season, but little correlation to the previous years. Furthermore, the small sample sizes analyzed for each year means that we do not necessarily see the same clusters of haplotypes unless they were dominant the year before. This hypothesis is interesting because it implies that $M$. grisea populations are characterized by extinction and recolonization of small subpopulations, as might be expected in metapopulations. To test this hypothesis further, we need to study population subdivision, which will require larger samples from individual locations. Under this model, we predict that we would see spatially subdivided populations.

\section{ACKNOWLEDGMENTS}

This research was supported by a grant (CG1415) from the Crop Functional Genomics Center of 21st Century Frontier Research Program funded by the Ministry of Science and Technology of the Korean government and a grant from the Agricultural Plant Stress Research Center funded by Korea Science and Engineering Foundation to Y.-H. Lee. Part of this work was supported by an overseas visiting fellowship to S.-Y. Park (at Cornell University) from the Brain Korea 21 Project. We thank N. Grünwald for sharing the program Rarefac.c and providing helpful advice on rarefaction analysis, and R. Nelson for critical reading of the manuscript.

\section{LITERATURE CITED}

1. Bandong, I. M., and Ou, S. H. 1966. The physiological races of Pyricularia oryzae Cav. in the Philippines. Philipp. Agric. 49:655-667.

2. Bonman, J. M., Vergel De Dios, T. I., Bandong, J. M., and Lee, E. J. 1992. Breeding rice for resistance to pests. Annu. Rev. Phytopathol. 30:507-528.

3. Brown, J. K. M. 1995. Pathogens' responses to the management of disease resistance genes. Pages 75-102 in: Advances in Plant Pathology. J. H. Andrews and I. C. Tommerup, eds. Academic Press, New York.

4. Carbone, I., Anderson, J. B., and Kohn, L. M. 1999. Patterns of descent in clonal lineages and their multilocus fingerprints are resolved with combined gene genealogies. Evolution 53:11-21.

5. Chen, D., Zeigler, R. S., Leung, H., and Nelson, R. J. 1995. Population structure of Pyricularia grisea at two screening sites in the Philippines. Phytopathology 85:1011-1020.

6. Correa-Victoria, F. J., and Zeigler, R. S. 1991. Stable resistance and pathogenic variability in the rice-Pyricularia oryza complex. Pages 240288 in: Rice in Latin America: Improvement, Management, Marketing. F. Cuevas-Perez, ed. Centro Internacional de Agricultura Tropical (CIAT), Cali, Colombia.

7. Don, L. D., Kusaba, M., Urashima, A. S., Tosa, Y., Nakayashiki, H., and Mayama, S. 1999. Population structure of the rice blast fungus in Japan examined by DNA fingerprinting. Ann. Phytopathol. Soc. Jpn. 65:15-24.
8. Don, L. D., Tosa, Y., Nakayashiki, H., and Mayama, S. 1999. Population structure of the rice blast pathogen in Vietnam. Ann. Phytopathol. Soc. Jpn. 65:475-479.

9. Ellingboe, A. H. 1992. Segregation of avirulence/virulence on three rice cultivars in 16 crosses of Magnaporthe grisea. Phytopathology 82: 597-601.

10. Ellingboe, A. H., Wu, B.-C., and Robertson, W. 1990. Inheritance of avirulence/virulence in a cross of two isolates of Magnaporthe grisea pathogenic to rice. Phytopathology 80:108-111.

11. Farman, M. L., Jackson, V., Iqbal, M. P., and Leong, S. A. 1996. MAGGY, a retrotransposon in the genome of the rice blast fungus Magnaporthe grisea. Mol. Gen. Genet. 251:665-674.

12. Grünwald, N. J., Flier, W. G., Sturbaum, A. K., Garay-Serrano, E., van den Bosch, T. B. M., Smart, C. D., Matuszak, J., Lozoya-Saldana, H., Turkensteen, L. J., and Fry, W. E. 2001. Population structure of Phytophthora infestans in the Toluca valley region of central Mexico. Phytopathology 91:882-890.

13. Hamer, J. E., Farrall, L., Orbach, M., Valent, B., and Chumley, F. G. 1989. Host species-specific conservation of a family of repeated DNA sequences in the genome of a fungal plant pathogen. Proc. Natl. Acad. Sci. USA 86:9981-9985.

14. Han, S.-S. 1996. Genetic variability and population structure of Korean isolates of Pyricularia grisea. Ph.D. diss. Tokyo University of Agriculture, Tokyo.

15. Han, S. S., Ra, D. S., and Nelson, R. 1993. Comparison of RFLP-based phylogenetic trees and pathotypes of Pyricularia oryzae in Korea. RDA J. Agri. Sci. 35:315-323.

16. Hutcheson, K. 1970. A test for comparing diversities based on Shannon formula. J. Theor. Biol. 29:151-154.

17. Iwano, M., Lee, J. L., Lee, C. Y., and Kong, P. 1990. Distribution of pathogenic races and changes in virulence of rice blast fungus, Pyricularia oryzae Cav., in Yunnan province, China. Jpn. Agric. Res. Q. 23:241-248.

18. Kiyosawa, S. 1982. Genetic and epidemiological modeling of breakdown of plant disease resistance. Annu. Rev. Phytopathol. 20:93117.

19. Kumar, J., Nelson, R. J., and Zeigler, R. S. 1999. Population structure and dynamics of Magnaporthe grisea in the Indian Himalayas. Genetics 152:971-984.

20. Latterell, F. M., and Rossi, A. E. 1986. Longevity and pathogenic stability of Pyricularia oryzae. Phytopathology 76:231-235.

21. Levy, M., Correa-Victoria, F. J., Zeigler, R. S., Hu, S., and Hamer, J. E. 1993. Genetic diversity of the rice blast fungus in a disease nursery in Colombia. Phytopathology 83:1427-1433.

22. Levy, M., Romao, J., Marchetti, M. A., and Hamer, J. E. 1991. DNA fingerprinting with a dispersed repeated sequence resolves pathotype diversity in the rice blast fungus. Plant Cell 3:95-102.

23. Liu, Y.-C., Cortesi, P., Double, M. L., MacDonald, W. L., and Milgroom, M. G. 1996. Diversity and multilocus genetic structure in populations of Cryphonectria parasitica. Phytopathology 86:13441351.

24. Mantel, N. A. 1967. The detection of disease clustering and a generalized regression approach. Cancer Res. 27:209-220.

25. Nei, M., and Li, W.-H. 1979. Mathematical model for studying genetic variation in terms of restriction endonucleases. Proc. Natl. Acad. Sci. USA 76:5269-5273.

26. Ou, S. H. 1980. Pathogen variability and host resistance in rice blast disease. Annu. Rev. Phytopathol. 18:167-187.

27. Rogers, S. O., and Bendich, A. J. 1985. Extraction of DNA from milligram amount of fresh, herbarium and mummified plant tissues. Plant Mol. Biol. 5:69-76.

28. Rohlf, F. J. 1989. NTSYS-pc Numerical Taxonomy and Multivariate Analysis System. Exeter Publishing, Setauket, NY.

29. Roumen, E., Levy, M., and Notteghem, J. L. 1997. Characterization of the European pathogen population of Magnaporthe grisea by DNA fingerprinting and pathotype analysis. Eur. J. Plant Pathol. 103:363371.

30. Shen, Y., Zhu, P., Yuan, X., Zhao, X., Manry, J., Rojas, C., Shahjahan, A. K. M., and Levy, M. 1996. The genetic diversity and geographic distribution of Pyricularia grisea in China. Sci. Agric. Sin. 29:39-46.

31. Silue, D., Notteghem, J. L., and Tharreau, D. 1992. Evidence of a genefor-gene relationship in the Oryza sativa-Magnaporthe grisea pathosystem. Phytopathology 82:577-580.

32. Silue, D., Tharreau, D., and Notteghem, J. L. 1992. Identification of Magnaporthe grisea avirulence genes to seven rice cultivars. Phytopathology 82:1462-2467.

33. Smith, J. M., Smith, N. H., O’Rourke, M., and Spratt, B. G. 1993. How clonal are bacteria? Proc. Natl. Acad. Sci. USA 90:4384-4388. 
34. Valent, B., and Chumley, F. 1994. Avirulence genes and mechanisms of genetic instability in the rice blast fungus. Pages 111-134 in: Rice Blast Disease. R. S. Zeigler, S. A. Leong, and P. S. Teng, eds. CAB International, Wallingford, UK.

35. Yap, I. V., and Nelson, R. J. 1996. Winboot: A program for performing bootstrap analysis of binary data to determine the confidence limits of UPGMA-based dendrograms. International Rice Research Institute Dis. Pap. Ser. 14.
36. Zeigler, R. S., Cuoc, L. X., Scott, R. P., Bernardo, M. A., Chen, D. H., Valent, B., and Nelson, R. J. 1995. The relationship between lineage and virulence in Pyricularia grisea in the Philippines. Phytopathology 85:443-451.

37. Zeigler, R. S., Tohme, J., Nelson, R., Levy, M., and Correa-Victoria, F. J. 1994. Lineage exclusion: A proposal for linking blast population analysis to resistant breeding. Pages 267-292 in: Rice Blast Disease. R. S. Zeigler, S. A. Leong, and P. S. Teng, eds. CAB International, Wallingford, UK. 